\title{
ANÁLISE DOS AGENTES PÚBLICOS DO SISTEMA NACIONAL DE ESPORTES DAS CIDADES DA AMUSEP ${ }^{1}$
}

Recebido em: 15/05/2016

Aceito em: 10/07/2017

Giovanna Xavier de Moura

Universidade Estadual de Maringá (UEM)

Maringá - PR - Brasil

Jeferson Roberto Rojo

Universidade Federal do Paraná

Curitiba - PR - Brasil

Andressa Peloi Bernabé,

Fernando Augusto Starepravo

Universidade Estadual de Maringá (UEM)

Maringá - PR - Brasil

RESUMO: O estudo objetivou problematizar se municípios de porte semelhantes, localizados na região da AMUSEP (Associação dos Municípios do Setentrião Paranaense/ referente a região norte do Estado) possuem condições distintas ou semelhantes no que diz respeito ao quadro de agentes e a gestão das políticas públicas de esporte e lazer. Os dados foram coletados através de entrevistas realizadas com agentes públicos de esporte e lazer de três cidades sorteadas, que foram analisadas por meio da Análise de Conteúdo de Bardin (2009). Foi possível perceber que, apesar dos municípios possuírem autonomia para gerir o esporte e o lazer a partir de suas especificidades, há uma semelhança nos aspectos, tais como perfil e formação dos agentes, estrutura burocrática, e modo de gestão do esporte e lazer.

PALAVRAS CHAVE: Políticas Públicas. Esportes. Atividades de Lazer.

\section{ANALYSIS OF PUBLIC MANAGERS OF THE NATIONAL SYSTEM OF SPORTS IN THE CITIES BELONGING TO AMUSEP}

ABSTRACT: The study aimed to question whether similar municipalities, located in the region of AMUSEP (Association of cities from the North region of Parana State) have different or similar conditions regarding the agent framework and the management of public policies of sports and leisure. The data were collected by means of interviews conducted with randomly selected public agents of leisure and sports from three cities. The interviews were analyzed by the Bardin Content Analysis (2009). It was possible to perceive that, although the municipalities have autonomy to manage

\footnotetext{
${ }^{1}$ A pesquisa foi financiada pelo $\mathrm{CNPq} /$ Ministério do Esporte (ME).
} 
the sport and leisure from their specifics, there is a similarity in aspects such as profile and formation of the agents, bureaucratic structure, and mode of management of the sport and leisure.

KEYWORD: Public Policies. Sports. Leisure Activities.

\section{Introdução}

A República Federativa do Brasil constitui-se em um Estado em que a relação entre os entes ligados a União é estabelecida pela Constituição Federal de 1988 (BRASIL, 1988). Segundo Arretche (2004), Estados com configurações semelhantes à do Brasil, tem como objetivo, além de garantir a união da nação, reduzir as desigualdades ao mesmo passo que entende que exista diversidade entre os entes.

Especificamente no caso brasileiro, a federação está dividida em três entes federados, sendo eles: a União, Estados/Distrito Federal e os municípios (ARRETCHE, 2010). Este último por sua vez, foi incorporado como ente federado e a partir da CF/88, pela qual passou a ter mais autonomia na produção da política sendo justificada pelos constituintes como forma de atingir as especificidades e as necessidades da realidade de cada localidade.

Dentre as políticas produzidas pelos municípios, estão as políticas públicas para o esporte e lazer. Segundo Starepravo (2011), a relação entre o esporte e o Estado se estreitou a partir da criação do Ministério do Esporte. Porém, a gestão municipal se depara com a falta de profissionais com formação para atuar na área (STAREPRAVO, 2011), havendo uma grande necessidade de qualificar os agentes para trabalhar no âmbito das políticas públicas de esporte e lazer.

A discussão acerca dos agentes envolvidos com as políticas públicas vem mobilizando não apenas o Ministério do Esporte, mas grande parte da comunidade envolvida com o esporte. Por iniciativa do Ministério foram organizadas três 
Conferências Nacionais do Esporte (CNE) que constituem em um espaço público de debate, formulação e deliberação das políticas públicas de esporte e lazer. Das Conferências, as duas primeiras discutiram centralmente a (re)construção do Sistema Nacional do Esporte $(\mathrm{SNEL})^{2}$, e a terceira CNE mudou o foco, discutindo especialmente sobre os megaeventos esportivos a serem realizados no Brasil.

A partir das duas primeiras Conferências Nacionais do Esporte, o SNEL começou a ser pensado a partir de alguns eixos fundamentais: estrutura, recursos humanos e formação, gestão e controle social, e o financiamento (BRASIL, 2006). Nesse sentido, pode-se perceber que os agentes ocupam posição central na estruturação do SNEL e das políticas públicas de esporte e lazer. Por outro lado, é reduzido o conhecimento sobre quem são e como atuam os agentes que compõe o SNEL (MEZZADRI et al., 2006). Cabe destacar ainda que a estruturação do SNEL tem por base o regime de colaboração entre a União, os Estados e os municípios, com ênfase na municipalização (BRASIL, 2006).

Os agentes públicos do sistema são os agentes responsáveis pela formulação e implementação de políticas públicas de esporte e lazer sejam em seu trabalho no Ministério do Esporte, em secretarias estaduais e municipais de esporte e lazer, ou ainda em conselhos de esporte e lazer, confederações, ONGs, escolas, entre outros. Os agentes públicos municipais do esporte e lazer são todas as pessoas que trabalham nas secretarias ou departamentos nos municípios.

Considerando então as especificidades de cada município e que o federalismo possibilita a autonomia dos municípios para geri-las, buscamos problematizar se

\footnotetext{
${ }^{2}$ O SNEL, apesar de ser colocado em discussão, não foi efetivado. No ano de 2015, retomaram-se as discussões acerca do possível sistema.
} 
municípios de porte semelhantes, localizados em uma mesma região (AMUSEP ${ }^{3}$ Associação dos Municípios do Setentrião Paranaense) possuem condições distintas ou semelhantes no que diz respeito ao quadro de agentes e a gestão das políticas públicas de esporte e lazer?

\section{Metodologia e Cuidados Éticos}

Trata-se de uma pesquisa descritiva direta, que foi realizada em municípios do Estado do Paraná, que fazem parte da AMUSEP, a região norte do Estado. Em primeiro lugar, o projeto foi enviado ao Comitê Nacional de Ética em Pesquisa, sendo aprovada pelo parecer $\mathrm{n}^{\circ}$ 548.551. Com a aprovação do projeto, as atividades que envolveram o estudo foram iniciadas. Considerando, então, que atualmente a AMUSEP é formada por um total de trinta municípios, e a cidade polo é Maringá, foi realizado um sorteio de três cidades da AMUSEP, representando $10 \%$ do total de cidades, para que a pesquisa pudesse ser realizada.

Após o sorteio dos municípios, foi realizado um primeiro contato telefônico com o órgão público municipal responsável pelo esporte e lazer (Secretaria Municipal de Esporte ou órgão equivalente) nessas cidades, a fim de explicitar os objetivos da pesquisa e solicitar o consentimento do município em participar do estudo. Neste contato, foi realizado também um levantamento do quantitativo de agentes públicos municipais que compõe o SNEL. Posteriormente ao consentimento do município e a identificação dos agentes, foram agendadas as visitas às cidades e as entrevistas.

\footnotetext{
${ }^{3}$ A Associação dos Municípios do Setentrião Paranaense é uma instituição privada, de utilidade pública, duração indeterminada e sem fins lucrativos no que se refere à sua atuação como órgão assessor/coordenador junto aos Municípios que a integram. Localizada na região noroeste do Paraná é composta pelos seguintes Municípios: Ângulo, Astorga, Atalaia, Colorado, Doutor Camargo, Florai, Floresta, Flórida, Iguaraçu, Itaguajé, Itambé, Ivatuba, Lobato, Mandaguaçu, Mandaguari, Marialva, Maringá, Munhoz de Mello, Nossa Senhora das Graças, Nova Esperança, Ourizona, Paiçandu, Paranacity, Presidente Castelo Branco, Santa Fé, Santa Inês, Santo Inácio, São Jorge do Ivaí, Sarandi e Uniflor.
} 
Foram entrevistados os sujeitos que atuam de maneira efetiva na gestão e desenvolvimento das políticas públicas de esporte e lazer, sendo eles vinculados à secretaria ou departamento responsável pelo esporte e lazer da cidade pesquisada. Estes assinaram um Termo de Consentimento Livre e Esclarecido, concordando em participar da pesquisa voluntariamente. As entrevistas eram semiestruturadas e seguiram um roteiro pré-estabelecido. Elas foram gravadas, transcritas e analisadas de acordo com os procedimentos descritos na Análise de Conteúdo proposta por Bardin (2009).

\section{Resultados e Discussão}

Em primeiro lugar, faz-se necessário apresentar aqui características dos municípios pesquisados em relação a área de extensão e número de habitantes, assim como o quadro de agentes, como consta no Quadro abaixo. Como forma de manter o sigilo dos municípios, utilizaremos M1, M2 e M3 para identificá-los.

Quadro 1 - Porte dos Municípios pesquisados

\begin{tabular}{c|c|c|c}
\hline MUNICÍPIOS & ÁREA & POPULAÇ̃̃̃O & PIB per Capita \\
\hline M1 & $175 \mathrm{Km}^{2}$ & 3.482 & $\mathrm{R} \$ 18.752,09$ \\
M2 & $95 \mathrm{Km}^{2}$ & 2.570 & $\mathrm{R} \$ 11.950,40$ \\
M3 & $185 \mathrm{Km}^{2}$ & 4.053 & $\mathrm{R} \$ 11.677,87$ \\
\hline
\end{tabular}

Fonte: www.amusep.com/sites/municipios

Com relação aos agentes de cada município, temos que o M1 possui um gestor, que ingressou na secretaria como cargo de confiança do prefeito e três professores contratados por uma empresa privada. O M3 possui um gestor e um professor para desenvolverem as ações de esporte e lazer na cidade. Já no M2 o departamento conta apenas com o gestor, uma vez que não existe quadro técnico. $\cdot$

Cabe aqui a observação de que os cargos de confiança, segundo Dias e Matos (2012), também chamados de comissionados dispensam os concursos públicos para 
atuarem, dessa forma estes cargos podem ser ocupados por pessoas que não fazem parte do serviço público e/ou servidores de carreira. Além disso, os autores apresentam as diferenças entre cargo em comissão e a função de confiança, sendo que o primeiro se refere ao cargo em que há funções e salários definidos e pode ser preenchido por qualquer pessoa, e o segundo se refere ao posto que deva ser assumido por uma pessoa que já faz parte da área administrativa e recebe gratificações.

A partir desta caracterização inicial, apresentaremos a análise das entrevistas realizadas com os agentes públicos do esporte e lazer desses três municípios da AMUSEP. As entrevistas com os três gestores e um professor foram transcritas e analisadas a partir da Análise de Conteúdo (BARDIN, 2009). Dessa forma, três categorias foram identificadas, sendo elas: "perfil dos gestores", "gestão pública de esporte e lazer", e "formação". Tais categorias foram utilizadas para a análise das condições existentes na realidade de cada município, se são semelhantes ou distintas. Nos sub-tópicos que seguem discutiremos cada uma delas. Para identificar os gestores e professor de cada município, de modo a manter o anonimato dos sujeitos, utilizamos as abreviaturas G1, G2, G3 e P1. Cabe aqui uma observação de que o G1 é do M1, o G2 do M2e o G3 e o P1 são do M3.

\section{Perfil dos Gestores}

Apresentaremos o perfil dos gestores e do professor entrevistados de acordo com o sexo, idade, escolaridade, renda, tempo de trabalho. Iremos também apresentar dados que dizem respeito ao cargo que ocupam dentro do município no órgão público municipal responsável pela oferta do esporte e lazer e a forma de contratação. 
Quadro 2 - Perfil dos Gestores e Professor (sexo, idade, escolaridade, renda, tempo de trabalho)

\begin{tabular}{c|c|c|c|c|c}
\hline SUJEITO & SEXO & $\begin{array}{c}\text { IDADE } \\
\text { (Anos) }\end{array}$ & ESCOLARIDADE & RENDA & $\begin{array}{c}\text { TEMPO DE } \\
\text { TRABALHO }\end{array}$ \\
\hline G1 & Masc. & 49 & $2^{\circ}$ Grau Completo & $\begin{array}{c}3-5 \\
\text { salários }\end{array}$ & 7 anos \\
G2 & Masc. & 39 & $2^{\circ}$ Grau Completo & $\begin{array}{c}1-3 \\
\text { salários } \\
1-3\end{array}$ & 10 anos \\
G3 & Masc. & 29 & Superior Completo & $\begin{array}{c}1-3 \\
\text { salários } \\
1-3\end{array}$ & 5 anos \\
P1 & Fem. & 36 & Superior Completo & 13 anos \\
\hline
\end{tabular}

Por meio do Quadro 2, podemos perceber que dois dos entrevistados possuem Ensino Superior completo com formação em Educação Física, sendo um gestor e um professor. Os outros dois entrevistados possuem apenas o $2^{\circ}$ Grau completo, sendo que um desses (G2) afirmou que conseguiu o registro profissional no CREF (Conselho Regional de Educação Física), sistema que orienta e fiscaliza o exercício das atividades dos Profissionais de Educação Física (CONFEF, 2010). O credenciamento junto ao CREF é adquirido quando se tem formação de Ensino Superior em Educação Física, ou como no caso deste gestor, não tem formação em Educação Física mas trabalha na área, no mínimo até a data prevista pelo CONFEF, garantindo o registro por ter trabalhado um longo período de tempo na área, como prevê a Resolução CONFEF nº 045/2002:

Art. $1^{\circ}$ - O requerimento de inscrição dos não graduados em curso superior de Educação Física, perante os Conselhos Regionais de Educação Física - CREFs, em categoria PROVISIONADO, far-se-á mediante o cumprimento integral e observância dos requisitos solicitados.

Art. $2^{\circ}$ - Deverá o requerente apresentar comprovação oficial da atividade exercida, até a data do início da vigência da Lei no 9696/98, ocorrida com a publicação no Diário Oficial da União (DOU), em 02 de Setembro de 1998, por prazo não inferior a 03 (três) anos, sendo que, a comprovação do exercício, se fará por:

I - carteira de trabalho, devidamente assinada; ou,

II - contrato de trabalho, devidamente registrado em cartório; ou,

III - documento público oficial do exercício profissional; ou,

IV - outros que venham a ser estabelecidos pelo CONFEF. 
Art. $3^{\circ}$ - Deverá, também, o requerente, obrigatoriamente, indicar uma atividade principal, própria de Profissional de Educação Física, com a identificação explícita da modalidade e especificidade.

Queiroz et al. (2011), em seu trabalho sobre “A Realidade Pública do Esporte nos Municípios da Região Médio Rio Grande do Estado de Minas Gerais”, apresenta características semelhantes no que se refere à escolaridade dos gestores municipais de esporte, ao afirmar que na região pesquisada há gestores que possuem apenas o Ensino Médio completo, sendo eles $23,5 \%$ do total dos gestores pesquisados, mas que $47,1 \%$ possui curso superior completo. $\mathrm{O}$ autor ainda afirma que os gestores com formação em Educação Física apresentam melhores resultados devido ao conhecimento adquirido na área. Entretanto, cabe aqui questionar se somente a formação em Educação Física seria suficiente para suprir as necessidades dos agentes nos municípios. Sendo assim, devem ser incentivados a busca pelo conhecimento por meio de cursos, eventos e reuniões que promovam interação entre os agentes de modo que auxilie as questões que envolvem o esporte e o lazer nos municípios.

Em se tratando dos cargos que estes gestores ocupam em seus municípios, devemos, antes de tudo, esclarecer as diferenças entre secretaria e departamento, uma vez que cada município pode apresentar um desses dois tipos de estrutura burocrática. Cabe aqui ressaltar que ambos, secretaria e departamento, são órgãos de administração direta, ou seja, estão diretamente ligados ao poder executivo em nível federal, estadual e municipal.

Uma secretaria tem "ampla autonomia administrativa, técnica e financeira [...] com funções de planejamento, supervisão, coordenação e controle das atividades que constituem sua área de competência" (CANEDO, 2007 p. 7). Diferentemente, quando se está em um departamento, este fica agregado a outra secretaria que divide as ações e 
financiamentos entre os vários departamentos que a compõe. Por exemplo, em uma Secretaria de Educação, Esporte e Cultura, o Departamento de esporte ligado à essa secretaria divide os investimentos e recursos com os outros departamentos ligados a ela, de Educação e Cultura.

Em relação ao contexto empírico pesquisado, dois dos gestores entrevistados são Diretores (G2 eG3), ou seja, trabalham em Departamentos, no caso do G2 em um Departamento de Esportes, e no caso do G3, juntamente com o P1, trabalham em um Departamento de Esporte e Lazer. Apenas um deles (G1) é Secretário, ou seja, trabalha em uma Secretaria de Esportes e Lazer. Isso significa que, no contexto pesquisado, prevalece a presença de departamentos em detrimento a secretarias, o que pode sugerir uma menor destinação de recursos ao esporte e lazer.

Em relação à forma de contratação desses gestores, temos que dois dos gestores (G2, G3) foram nomeados para assumir seus cargos. Outro meio para se chegar aos cargos seria por contratação, como G1 e P1. No caso do M1, município do G1, prefeitura contrata uma empresa e a empresa contrata os professores para trabalhar com a área de esporte e lazer. Muitas dessas nomeações e indicações para tais cargos ocorrem devido o tempo de trabalho dessas pessoas na área, como no caso do P1, ou por ter jogado em um time da cidade, trabalhar com escolinhas de futebol e como estagiário de Educação Física, como o G3, dentre outras possibilidades. Nestes casos o conjunto de capitais (BOURDIEU, 2009) dos agentes (social e esportivo especialmente) parecem ser decisivos para a inserção como agente público municipal. Cabe aqui ressaltar que em casos de indicação, não há necessidade de ter uma formação na área de esporte e lazer, diferentemente do concursado, que em geral há a exigência de uma formação específica. 
Já em relação à renda dos agentes que participaram da pesquisa, percebe-se, como pode ser verificado no Quadro 2, que a maioria (3) - dois gestores e um professorganha entre um a três salários mínimos, ou seja, o valor entre R\$ 788 e R\$ 2.364 (valores de 2015), e apenas um dos entrevistados ganha de três a cinco salários mínimos (valor entre 2.364 e 3.940 reais). O tempo de trabalho dos entrevistados varia de cinco a treze anos.

Vale ressaltar que um dos gestores, G1, é um dos que não tem a qualificação de Ensino Superior e nem o maior tempo de experiência. Entretanto, este é o que recebe o maior salário dos entrevistados, sendo que o P1 possui formação completa, trabalha 6 anos a mais que o G1 mas seu salário é inferior, ou seja, formação neste caso não representa salário maior, o que prevalece é o aspecto político em um cargo político. Neste caso o capital político prevalece sobre o capital cultural institucionalizado, representado pela posse de diplomas ou certificados que objetivam um processo de escolarização (BOURDIEU, 2005). Entretanto, como citado anteriormente, o cargo apresentado pelo G1 é de secretário, o que pode justificar sua maior remuneração.

Ao analisar as condições existentes em relação ao perfil do gestor e a estrutura burocrática do esporte e lazer de cada município, observa-se que as características são próximas, sendo que algumas poucas exceções foram diagnosticadas.

\section{Formação de Gestores}

Neste tópico trataremos sobre aspectos relacionados à formação e qualificação dos gestores responsáveis pela política pública esportiva e de lazer dos municípios, ou seja, apresentaremos sobre o acesso à informação relacionada ao esporte e lazer, a 
realização de cursos de capacitação para o cargo em que atuam e o incentivo dos próprios municípios à formação e qualificação dos gestores.

Referente ao acesso à informação, todos os gestores afirmaram utilizarem a internet como principal meio de obter informações, ao qual tem acesso todos os dias, principalmente para pesquisas relacionadas ao esporte como, site da Paraná Esporte, site do núcleo de educação, do CREF, site Globo Esporte ou ainda para busca de projetos e documentações importantes. Outros meios de acesso citados foram à televisão, rádios e revistas, que são meio superficiais de acesso à informação pois não possuem um teor científico ou acadêmico. São meios mais fáceis e rápidos de se obter informação, e que, na rotina, acabam sendo os mais acessíveis em detrimento a outras fontes, como livros por exemplo. Mesmo utilizando desses meios, os gestores ainda mencionaram os cursos de capacitação como uma forma de adquirir conhecimento para atuarem em suas funções.

Ao abordarmos sobre os cursos, os gestores, em sua maioria, procuram cursos de capacitação para se qualificarem e se instruírem sobre o esporte. Galindo e Moraes (2004; 2005) sugerem ciclos de conferências de esporte e lazer para auxiliar na elaboração de políticas públicas. Menezes, Oliveira e Souza (2012) complementam que podem ser realizados fóruns, reunindo os municípios mais próximos para troca de informações referentes ao setor esportivo, seja de gestão ou de desenvolvimento de políticas de ações esportivas.

$\mathrm{Na}$ fala de um dos gestores $(\mathrm{G} 3,2014)$ podemos verificar a realização de um desses meios apontados pela literatura, um curso específico para os gestores do esporte, curso que é realizado pelo Estado nos últimos anos, em cidades diferentes: “[...] eu busco conhecimento em internet, palestras, onde que tiver. Igual teve um curso em Foz 
do Iguaçu dos gestores de esporte que eu fui, então onde que ta no meio do esporte eu gosto de interagir". Há também reuniões realizadas pelos diretores de esportes das regiões, como citado pelo G3 (2014), em que colocam em pauta os pontos principais de suas gestões e juntos procuram soluções e auxílio: "Então, sempre nós reúne aqui os da região, os diretores de esportes sempre fazem uma reunião, vendo qual é as qualidades, pontos positivos de um do outro, se aqui não ta dando certo na cidade vizinha ta dando, se busca la fora o que está dando certo, e eles veem a mesma coisa com a gente, eles vem tira ideia, opiniões. [...]"

Além disso, os gestores participam de cursos relacionados ao esporte de alto rendimento, obesidade, ou ainda de cursos de verão sobre recreação. Apenas um dos gestores, G1, diz não realizar esses cursos e utiliza a experiência como forma de se qualificar. Em ressalva a esses aspectos, Queiroz et al. (2011) afirmam que capacitar o gestor com cursos não soluciona os problemas existentes, irá apenas reduzir e solucionar alguns desses problemas, uma vez que não há uma formação mais ampla, e sim cursos de capacitação esporádicos, e na maioria das vezes de curta duração.

Esses cursos muitas vezes são incentivados pelas próprias secretarias ou departamentos, sendo que estes chegam até a financiar as viagens, como afirma G2 e P1. Em outros casos, quando o gestor se interessa por cursos e não há verba suficiente, ele mesmo paga os custos necessários à participação.

Quando questionados sobre quais os conhecimentos necessários para o trabalho que desempenham como gestores e professores de esporte e lazer, dois dos três gestores (G1 e G3) entrevistados afirmam que é necessária a formação em educação física e ser um profissional capacitado, ou seja, esse profissional deve entender da área, conhecer os métodos, os materiais. Entretanto, houve uma contradição na fala de um dos gestores, 
quando diz que a capacitação profissional é importante, mas julga ser necessário apenas a experiência para desenvolver seu trabalho. Tal posicionamento pode estar relacionado ao fato desse gestor não ter formação em Educação Física.

O outro gestor (G2) e o professor (P1) asseguram que é necessária a participação em cursos e palestras, mas que estes são pouco divulgados, e também ter o conhecimento de outras áreas e de outros departamentos para realizar um trabalho bem feito. Mesmo acreditando que a intersetorialidade se faz necessária, durante as entrevistas os agentes não demonstraram buscá-la.

Galindo (2005, p. 55) afirma que deve sim haver um:

[...] equilíbrio dinâmico da gestão do desporto e lazer na cidade, através de uma integração do governo nas áreas de educação, esporte, lazer, saúde, cultura e ação social, garantida nos diversos instrumentos de planejamento municipal, e de gestão urbana.

Dessa forma, garantindo a articulação entre as diferentes áreas pode-se desenvolver melhor os trabalhos dentro das secretarias, ou seja, contribuir de maneira mais eficaz pela elaboração de projetos e atividades que trabalhem o cidadão de forma geral, obtendo melhores resultados.

Como observado nas informações contidas nos relatos dos depoentes, apenas um dos gestores faz menção a não realizar cursos ou outra forma de capacitação e formação dos agentes do esporte e lazer do município. Esse fato mostra que há certa semelhança entre os municípios pesquisados em relação à categoria formação.

\section{Gestão Pública de Esporte e Lazer}

Nesta categoria serão expostas informações sobre os significados de esporte e lazer para os agentes e como eles ofertam esses direitos em seus municípios, sobre os 
espaços e equipamentos que cada um dos municípios possui, além das verbas e financiamentos de projetos e programas, e por fim sobre a autonomia dos municípios.

Em primeiro lugar, faz-se relevante apresentar aqui qual a visão dos gestores acerca do entendimento de esporte e lazer. Dois dos gestores (G1 e G2) apresentaram o esporte como um meio social, como uma forma de envolver as pessoas, principalmente as crianças e tirando-as da rua, como uma forma de ensinamentos e formação de caráter, expressas nas palavras do G2 (2014): “o esporte é a base de tudo, quando você pratica esportes você esquece do mundo, você esquece de droga, você esquece de maldade, no esporte não tem raça, não tem cor, não tem diferença, no esporte você é igual a todos [...] é a base de tudo na formação do ser humano".

Melo (2005) trata sobre o caráter salvacionista do esporte criticando esse discurso político que visa manter jovens longe da criminalidade, por associar o esporte a encobrir e solucionar os problemas da sociedade.

Os outros dois gestores aproximam-se do significado de esporte com a vida. P1 (2014) afirma que o esporte se refere ao movimento do corpo, que em todas as atividades do dia-a-dia estamos nos exercitando, sendo assim, para ele: "esporte é vida". O segundo, o G3 (2014), apresenta que o esporte esteve presente, na vida dele, em todos os momentos desde pequeno, “então, o esporte pra mim é meu dia a dia, é minha vida, o que eu penso e respiro é esporte".

Segundo Marchi Júnior e Afonso (2007), esporte é considerado como um evento econômico, social, processual, histórico e culturalmente construído, que tem se popularizado devido a representação na sociedade de atividade física acessível a todos. Ainda, de acordo com Proni (2011), o esporte está cada vez mais difícil de ser definido 
antropológico-culturalmente e pelas relações e estruturas sociais. Devido às suas alterações de significado, sua definição deve ser ampla, flexível e inclusiva.

Já com relação ao lazer, podemos considerar que a maior parte dos gestores afirma o lazer como recreação, o que para eles seria o jogar, o brincar, o levar para passear. Além disso, apresentam também o lazer no sentido de descanso, ou seja, ter um momento durante a semana ou o dia para relaxar. Vale enfatizar que os gestores confundem os termos lazer e recreação, tema central de Gomes (2013, p. 296) em sua tese de doutorado, que destaca que

\begin{abstract}
A recreação pode ser compreendida como sinônimo de atividades realizadas com o intuito de promove diversão, especialmente aquelas desenvolvidas a partir da atuação de uma liderança (profissional ou voluntária) que conduz as ações propostas. Nesse sentido, a recreação preserva o caráter da atividade. As atividades recreativas são diversas e não são exclusivas dos momentos de lazer, podendo ser vivenciadas em diversos tempos/espaços sociais [...].
\end{abstract}

Os dados evidenciam que os gestores entrevistados não tem conhecimento aprofundado sobre o lazer, apenas suas experiências de vida. Ainda assim, podemos identificar em suas falas características do lazer exposta por autores, como por exemplo, a definição de Marcellino (1990, p. 32) "como cultura compreendida no seu sentido mais amplo vivenciada (praticada ou fruída) no tempo disponível” ou ainda a definição de Dumazedier (1973, p. 34), que se enquadra às respostas dadas:

O lazer é um conjunto de ocupações às quais o indivíduo pode entregar-se de livre vontade, seja para repousar, seja para divertir-se, recrear-se e entreter-se, ou ainda, para desenvolver sua informação ou formação desinteressada, sua participação social voluntária ou sua livre capacidade criadora após livrar-se ou desembaraçar-se das obrigações profissionais, familiares e sociais.

Entretanto, o que se percebe, tanto com relação a concepção de esporte quanto a concepção de lazer, é que os agentes não conseguem compreendê-los em sua complexidade e totalidade, sendo que existe a possibilidade de não terem 
fundamentação teórica para concebê-los, sendo que o conceito de lazer, sem definição concreta, fica limitado à recreação.

Uma vez apresentado o conceito de esporte e lazer para os gestores entrevistados, a partir de agora seguiremos com exposição sobre como estas duas manifestações são trabalhadas dentro de cada um dos municípios.

Quanto aos espaços e equipamentos, todos os municípios possuem um campo de futebol, um ginásio de esportes ou uma quadra. Entretanto, os gestores assumem que estes espaços não são suficientes para realizar todas as atividades que gostariam de realizar e que, por isso, muitas vezes é necessário utilizar espaços improvisados. Além disso, alguns municípios têm a previsão de construção de quadras de areia, campos de futebol suíço, academias e locais para realização de ginásticas e alongamentos e também de reformas destes locais, que muitas vezes se encontram em condições precárias.

Estes espaços são utilizados para treinamentos de escolinhas de futebol e futsal nas categorias feminino e masculino e para recreações em datas comemorativas nos municípios M1, M2 e M3, como por exemplo no Dia das Crianças. São utilizados também para o treinamento de outras modalidades como o handebol (M1) e vôlei (M3). Em alguns deles, são promovidas atividades como ginástica e caminhada para a terceira idade (M1, M2, M3), oficinas de karatê e de capoeira (M3), de dança e de artesanato (M3), ou ainda em apresentações dos alunos (M3) e campeonatos internos ou regionais (M1, M2, M3), no caso do M2, há competições de futebol para veteranos. Em um dos municípios, o gestor enfatizou que procuram incluir os alunos da APAE (Associação de Pais e Amigos dos Excepcionais) nestas atividades. Foi possível perceber que há uma diferença quanto as atividades citadas pelo G3 e as citadas pelo P1 quanto ao trabalho 
realizado no município em que atuam - o M3 - como por exemplo, o G3 cita os treinamentos de vôlei e o P1 não, assim como o P1 cita atividades para a terceira idade, como caminhadas e artesanato e o G3 não faz comentários sobre essas atividades.

Mesmo com algumas atividades diferenciada realizadas de forma isoladas, é de percepção que a grande maioria das ações oferecidas pela gestão de esporte e lazer dos municípios são desenvolvidas a partir de eventos. Essas ações são vistas como frágeis e passageiras (MEZZADRI et al. 2006). Segundo os autores, tais propostas não se consolidam como projetos permanentes, o que seria a essência de qualquer política pública para o esporte e lazer. Mezzadri e seus colaboradores, afirmam, que essa realidade pode ser explicada pela falta de projetos da gestão anterior, ou pela ruptura de mandatos eletivos que prejudicou o desenvolvimento deste tipo de programa.

Ainda sobre a gestão esportiva, Queiroz et al. (2011) afirma que, na realidade dos municípios que pesquisaram, não há atividades para todas as idades, ou seja, há certos grupos que não são contemplados nas atividades e ações propostas. Entretanto, em nossa pesquisa com os municípios pertencentes a AMUSEP, fica visível que há a preocupação em atender diferentes grupos de faixa etária, como crianças ou idosos, ou ainda, como citado acima, inclusão de grupos com necessidades especiais, como o caso do município que oferta atividades a integrantes da APAE.

Outro fator interessante é que o objetivo destas atividades, de acordo com a fala dos entrevistados, volta-se ao desenvolvimento do esporte social, ou esporte participativo. Na visão dos gestores, esporte participativo é "tudo quanto é tipo de evento [...] desde datas comemorativas, [...] é gincana, é rua de lazer [...]a ginástica né [...] a gente tem as oficinas de Karate, de capoeira, tem de dança" (P1, 2014). Apenas um dos gestores afirmou que em seu município há também o foco do esporte 
rendimento, que, segundo Galindo (2005), é o esporte que se refere a performances atléticas para se obter resultados.

Podemos perceber que dentro dos municípios, o esporte é trabalhado apenas em dois níveis citados por Queiroz (2011), que são o esporte participativo, que é aquele em que o cidadão participa de modo voluntário a fim de contribuir para sua qualidade de vida e integração; e o esporte rendimento, já citado anteriormente. Ainda há o esporte de formação, também chamado de educacional, que é o esporte praticado em sistemas de ensino, porém este não foi mencionado pelos entrevistados. Segundo Queiroz (2011), a função dos gestores seria proporcionar todos esses níveis de esporte para a população.

O que é valido ressaltar é que mesmo nos municípios em que os agentes dizem ser esporte de participação, podemos perceber quanto as atividades citadas anteriormente, que estes levam seus alunos, crianças, adolescentes e veteranos para campeonatos, o que poderia caracterizar o esporte de rendimento.

Além disso, segundo o Art. 217 da Constituição de 1988: “É dever do Estado fomentar práticas desportivas formais e não-formais, como direito de cada um, observados [...] a destinação de recursos públicos para a promoção prioritária do desporto educacional $[\ldots]$ ”. Contudo, o que se observa é que os agentes não citaram durante as entrevistas o esporte educacional, sendo que este deveria ser a prioridade nas ações do Estado para o campo esportivo.

Ainda com relação às atividades e eventos promovidos pelos municípios, os gestores as programam no início do ano, entretanto, muitas das vezes, o orçamento oferecido pela prefeitura ou secretaria não é o suficiente para desenvolvê-las. Com o valor determinado para a área do esporte, muitas vezes não conseguem deslocar as crianças para jogos, ou ainda a cada ano realizam atividades, campeonatos, recreação 
para um dos grupos etários pois para todos não é possível. Segundo os gestores, o poder público prioriza outros setores deixando o esporte e o lazer com recursos limitados. Os dizeres do G3 (2014) corroboram com essa explanação: “[...] A prioridade é sempre saúde e educação, mas o esporte ele fica numa última opção, a vamos olhar primeiro a saúde, educação, segurança, transporte, esporte sempre fica o último”. A esse respeito, Zingoni (2003) citado por Queiroz et al. (2011, p. 78) afirma que "ainda existem Secretarias de Esporte que reforçam as desigualdades sociais, a banalização do lazer”.

Por conta disso, empresas garantem um apoio externo, entretanto, este apoio ocorre em forma de auxilio material como medalhas e premiações dos campeonatos promovidos, e materiais esportivos como por exemplo bolas. Sendo assim, os gestores consideram que, mesmo com o apoio e financiamento de empresas neste sentido, o que recebem ainda não é suficiente para o trabalho e o planejamento que gostariam de realizar, já que esse auxílio ocorre, na maioria das vezes, de maneira pontual, apenas no período de campeonatos.

Além disso, devido a limitação financeira, não há recurso humano o bastante para desenvolver as atividades. Em alguns casos, como o do G2 (2014), só há o próprio gestor para desempenhar diversas funções: “Aqui no Departamento de Esporte (...) trabalho só eu, eu tenho que fazer tudo. Eu tenho que ser o treinador, o secretário, o roupeiro, o massagista. Eu treino várias categorias, eu tenho 8 categorias, masculino e feminino, e é difícil, muito difícil, e não tem profissional (...)”.

Miranda et al. (2002), Mezzadri et al (2006), Queiroz et al (2011), e Menezes, Oliveira e Souza (2012) apresentam em seus trabalhos informações semelhantes referentes ao apoio dado ao setor esportivo nos municípios. Os autores corroboram o que foi apontado pelos gestores, de que os patrocínios e apoios, tanto de empresas como 
da própria prefeitura, são restritos a realização de campeonatos, deslocamento de atletas para eventos fora do município, descritas como "políticas de atividade", ou ainda por meio de doação de materiais esportivos. Além disso, afirmam que não há incentivo a participação humana ou ações ordenadas e planejadas estrategicamente para a melhoria do setor.

Com essa limitação de recursos, seja financeiro ou humano, os gestores trazem a proposta de seus departamentos serem desvinculados de outras secretarias/departamentos e que não dependam única e exclusivamente da prefeitura. A grande reclamação dos gestores é que, muitas vezes prazos são perdidos, cronogramas ficam limitados, devido a impossibilidade de controle do orçamento e divisão do mesmo com outras áreas. Assim, uma vez que forem menos dependentes, as secretarias próprias para o esporte e lazer poderiam contar com seu próprio orçamento e assim poderia “andar com as próprias pernas" (G1, 2014), ou seja, se tornaria mais fácil a organização de eventos, compra de materiais, atendimento todas as categorias, pois os gestores poderiam controlar melhor o orçamento anual e distribuí-los de acordo com a necessidade.

Menezes, Oliveira e Souza (2012, p. 223) em pesquisa similar em regiões de Recife, apresentaram o pensamento de um dos gestores semelhante ao dos gestores da AMUSEP: "do ponto de vista do governo, uma decisão política de ampliar a estrutura da Diretoria de Esportes. Sem isso, ficamos muito presos e limitados, não vendo perspectiva de ampliar e descentralizar as ações".

Percebe-se então, que a intenção dos gestores é no sentido de uma diminuição da dependência organizacional e de como utilizar os recursos disponíveis para a realização das atividades propostas. 
Ao partir da compreensão do entendimento dos conceitos de Esporte e Lazer por parte dos agentes depoentes, é possível visualizar que há semelhança entre os municípios nesse sentido. Em seguida, ao referir-se a estrutura física existente nas cidades pesquisadas, ou seja, as instalações esportivas, foi diagnosticado que todas as cidades possuem instalações semelhantes. Além de não serem suficientes para as práticas desejadas, algumas estão em condições precárias e esperando por reformas.

Em relação às ações desenvolvidas, fica claro que, a partir das falas dos depoentes, na maioria dos casos as atividades realizadas nos municípios são semelhantes e em geral, a política é baseada na realização de eventos comemorativos. Os projetos desenvolvidos são realizados sob a perspectiva do esporte participativo, sendo que apenas um dos entrevistados faz menção ao esporte de rendimento.

Outro ponto de similaridade entre os municípios é no que tange aos recursos destinados a pasta do esporte e lazer. Todos os gestores entrevistados apontam que há limitação financeira para se trabalhar o esporte e lazer em suas respectivas cidades, intentando a desvinculação do departamento de esportes das pastas em que dividem espaço com outros departamentos.

\section{Considerações Finais}

Este trabalho teve como objetivo problematizar se municípios de porte semelhantes, localizados na região da AMUSEP (Associação dos Municípios do Setentrião Paranaense), possuem condições distintas ou semelhantes no que diz respeito ao quadro de agentes e a gestão das políticas públicas de esporte e lazer, considerando os pressupostos do federalismo instituído no Brasil, vez que, do ponto de vista teórico, 
dada a autonomia administrativa e financeira dos municípios, esperava-se encontrar situações bastante distintas entre os municípios pesquisados.

Por meio dos dados coletados, foi possível perceber a carência relacionada à formação dos gestores e professores para atuar na área de esporte e lazer, uma vez que apenas dois deles possuem curso superior na área. Além disso, apesar de acreditarem que a participação em cursos é necessária para atualizar as informações sobre o esporte e lazer, a busca por esses conhecimentos também é pequena. Ao que se refere à estrutura burocrática, tem-se que a maior parte dos municípios possui um Departamento de esportes, dividindo o espaço da Secretaria com outros departamentos. Assim, ao nos atentarmos ao perfil dos gestores e a estrutura burocrática do esporte e lazer dos municípios pesquisados, denota-se que em grande parte dos municípios as condições destes aspectos são semelhantes.

Em relação à compreensão dos conceitos de Esporte e Lazer, verifica-se semelhança entre os municípios, pois os agentes entrevistados possuem conceitos limitados e não conseguem compreendê-los em sua complexidade e totalidade. Sobre a as instalações para o esporte e o lazer, as três cidades pesquisadas possuem estruturas semelhantes como campo de futebol e ginásio poliesportivo, sendo que nem todas essas estruturas possuem condições de serem utilizadas.

No que se refere às ações desenvolvidas para o esporte e o lazer, a partir da fala dos entrevistados, na grande maioria dos municípios são destacadas as atividades baseadas na realização de eventos comemorativos e recreativos sob a perspectiva do esporte participativo, o que caracteriza em similaridades. Os agentes consideram que o desenvolvimento do esporte e lazer dentro dos municípios se dá pelo meio social, como base para a formação de crianças e jovens, sendo esta a importância do trabalho 
realizado por eles. Mas há uma contraposição ao relatarem que levam estes alunos para campeonatos, fato que pode ser caracterizado como esporte de rendimento em detrimento aos meios participativos e socializados, uma vez que campeonatos e competições limitam a participação de certo número de indivíduos e via de regra apenas premiam os mais habilidosos.

Além disso, quando se trata de investimentos e recursos nesses setores, há também semelhanças. Os gestores ressaltam que há dificuldades em atender todos os grupos da sociedade e envolver todos os projetos planejados devido ao orçamento restrito, limitação de recursos humanos, ou ainda pelo fato do esporte e lazer não serem prioridade nas prefeituras. Os gestores sugerem a criação de secretarias ou órgãos próprios para o desenvolvimento do esporte e lazer de modo que possam ter mais autonomia para organizar, de maneira mais eficiente, os eventos e projetos e realizar o trabalho de forma adequada.

Considerando então, a problemática proposta por esta pesquisa em verificar se municípios de porte semelhantes, localizados na região da AMUSEP, possuem condições distintas ou semelhantes no que diz respeito ao perfil, estrutura burocrática, formação e gestão de esporte e lazer, foi possível verificar que há uma semelhança entre os municípios pesquisados apesar de possuírem autonomia para gerir o esporte e o lazer a partir de suas especificidades. Assim, sugere-se que outros elementos explicativos devem ser problematizados a fim de se compreender porque, perante um quadro de inúmeras possibilidades, os municípios tendem a apresentar quadros semelhantes no que diz respeito ao desenvolvimento de políticas públicas de esporte e lazer. 
Propõe-se então que, pensando em questões como a autonomia dos municípios, estudos sejam realizados buscando analisar a gestão do esporte e do lazer em municípios de diferentes tamanhos, regiões e Estados.

\section{REFERÊNCIAS}

ARRETCHE, M. Federalismo e Políticas Sociais no Brasil: problemas de coordenação e autonomia. São Paulo em Perspectiva, São Paulo: v. 18, n. 2, 2004, p. 17-26.

ARRETCHE, M. Federalismo e igualdade territorial: uma contradição em termos? Revista de Ciências Sociais, Rio de Janeiro, v. 53, n. 3, 2010, p. 587-620.

BARDIN, L. Análise de Conteúdo. Lisboa: Edições 70, LDA, 2009.

BOURDIEU, P. A casa do rei à razão de Estado: um modelo da gênese do campo burocrático. In: WACQUANT, L. O mistério do ministério - Pierre Bourdieu e a política democrática. Loïc Wacquant (Org.) - Rio de Janeiro: Revan, 2005.

.O poder simbólico. Tradução Fernando Tomaz, 12. ed. Rio de Janeiro: Bertrand Brasil, 2009.

BRASIL. Constituição (1988). Constituição da República Federativa do Brasil. Brasília: Senado Federal, 1988.

BRASIL. Ministério do Esporte. CONFERÊNCIA NACIONAL DO ESPORTE, 2. II Fundamentação Sobre o Sistema Nacional de Esporte e Lazer. Brasília, 2006.

CANEDO, D. Secretaria da Cultura ou Fundação Cultural? ENCONTRO DE ESTUDOS MULTIDISCIPLINARES EM CULTURA, 3. Anais... Salvador, 2007. Disponível em: www.http://cult.ufba.br/enecult2007/DanielePereiraCanedo.pdf. Acesso em: 13 mar 2016.

CONSELHO FEDERAL DE EDUCAÇÃO FÍSICA, 2010. Disponível em: https://www.confef.org.br/extra/conteudo/default.asp?id=471. Acesso em: 2 jun. 2015.

DIAS, R; MATOS, F. Políticas Públicas: princípios, propósitos e processos. São Paulo: Atlas, 2012.

DUMAZEDIER, J. Lazer e Cultura Popular. São Paulo: Ed. Perspectiva S. A. 1973.

GALINDO, A. G. Esporte e lazer municipal: reflexões sobre as bases do planejamento e gestão pública. Revista do Plano Diretor Participativo do Município de Santana-AP - $\quad$ v. 1 - $\quad$ Num.1 - $\quad$ Out 2005. Disponível em: http://www.ceap.br/artigos/ART27082009163226.pdf . Acesso em: 19 maio 2013. 
GALINDO, A. G.; MORAES, R. S. Análise dos Resultados obtidos no $1^{\circ}$ ciclo de conferências do Esporte no Estado do Amapá: subsídios iniciais visando a elaboração de políticas públicas para o esporte e o lazer. Revista Cinergis. Santa Cruz do Sul, v.5, n.2, jul/dez, 2004. P. 9-28.

GOMES, C.L. Significados de recreação e lazer no Brasil: reflexões a partir da análise de experiências institucionais (1926-1964). Tese de Doutorado, Universidade Federal de Minas Gerais, 2013.

MARCELLINO, N. C. Lazer e Educação. 2. ed. Campinas: Papirus, 1990.

MARCHI JR, W.; AFONSO, G. F. Globalização e esporte: Apontamentos introdutórios para um debate. In: RIBEIRO, L. Futebol e Globalização. Jundiaí: Fontoura, 2007.

MELO, M. P. Esporte e juventude pobre: as políticas públicas de lazer na Vila Olímpica da Maré. Campinas: Autores Associados, 2005.

MENEZES, V. G.; OLIVEIRA, A. M.; SOUZA, E. F. Gestão Desportiva e Política Pública na Região Metropolitana de Recife. Revista Brasileira de Educação Física e Esporte. São Paulo, v.26, n.2, p. 219-30, abri/jun 2012.

MEZZADRI, F. M., et al. Políticas públicas para o esporte e o lazer nas cidades do estado do Paraná. In: MEZZADRI, F. M.; CAVICHIOLLI, F. R.; SOUZA, D. L. de. (Org.) Esporte e Lazer: subsídios para o desenvolvimento e gestão de políticas públicas. Jundiaí: Fontoura, 2006.

MIRANDA, M. et al. As políticas públicas esportivas do Rio Grande do Norte no ano de 2001. In: FÓRUM BRASILEIRO DE EDUCAÇÃO FÍSICA E CIÊNCIA DO ESPORTE. Universidade Federal de Viçosa. Minas Gerais, 2002. P. 376

PRONI, M. W. Proposições para o estudo do esporte contemporâneo. Curitiba, v. 1, n.1, p. 166-182, setembro 2011.

QUEIROZ, C. A. et al. A Realidade Pública do Esporte nos municípios da Região Médio Rio Grande do Estado de Minas Gerais. Passos: FESP, 2011.

STAREPRAVO. Políticas públicas de esporte e lazer no Brasil: aproximações, intersecções, rupturas e distanciamentos entre os subcampos político/burocrático e científico/acadêmico. Tese (Doutorado em Educação Física) - Universidade Federal do Paraná, Curitiba, 2011.

ZINGONI, P. Descentralização e Participação em Gestões Municipais de Esporte e Lazer. In: WERNECK, C. L. G.; ISAYAMA, H. F. Lazer, Recreação e Educação Física. Belo Horizonte: Autêntica, 2003. 


\section{Endereço dos Autores:}

Giovana Xavier de Moura

Universidade Estadual de Maringá (UEM)

Grupo de Estudos e Pesquisa em Políticas Públicas de Esporte e Lazer (GEPPOL-UEM)

Av. Colombo, 5790 - Zona 7

Maringá - PR - 87.020-900

Endereço Eletrônico: giovannax.moura@hotmail.com

Jeferson Roberto Rojo

Universidade Estadual de Maringá (UEM)

Grupo de Estudos e Pesquisa em Políticas Públicas de Esporte e Lazer (GEPPOL-UEM) Av. Colombo, 5790 - Zona 7

Maringá - PR - 87.020-900

Endereço Eletrônico: jeferson.rojo@hotmail.com

Andressa Peloi Bernabé

Universidade Estadual de Maringá (UEM)

Grupo de Estudos e Pesquisa em Políticas Públicas de Esporte e Lazer (GEPPOL-UEM)

Av. Colombo, 5790 - Zona 7

Maringá - PR - 87.020-900

Endereço Eletrônico: andressa.bernabe@hotmail.com

Fernando Augusto Starepravo

Universidade Estadual de Maringá (UEM)

Grupo de Estudos e Pesquisa em Políticas Públicas de Esporte e Lazer (GEPPOL-UEM)

Av. Colombo, 5790 - Zona 7

Maringá - PR - 87.020-900

Endereço Eletrônico: fernando.starepravo@hotmail.com 